\title{
GAMBARAN ADAPTASI FISIOLOGIS DAN PSIKOLOGIS PADA PASIEN GAGAL GINJAL KRONIS YANG MENJALANI HEMODIALISIS DI KOTA MANADO
}

\author{
Gracia Mait $^{\mathrm{a}^{*}}$, Muhammad Nurmansyah ${ }^{\mathrm{b}}$, Hendro Bidjuni ${ }^{\mathrm{c}}$ \\ ${ }^{a b c}$ Program Studi Ilmu Keperawatan Fakultas Kedokteran Universitas Sam Ratulangi \\ Manado, Indonesia \\ *Email : graciasteyne13@gmail.com
}

\begin{abstract}
Background: Chronic kidney failure is a disease that is suffered by many people in the world from young age to old age which significantly affects their ability and quality of life because they have to undergo therapy including hemodialysis. To increase adherence, the factors of adjustment to hemodialysis therapy need to be known in detail. Aim: to describe the physiological and psychological adaptation features in patients with chronic renal failure undergoing hemodialysis. Method: This study used descriptive analytical research method using simple random sampling with a total sample of 49 patients undergoing hemodialysis. The research instrument used is a questionnaire with quantitative data analysis techniques. Result: Respondents in this study have a good physiological adaptation (adaptive) that is $98 \%$ and also a good psychological adaptation that is

100\%. Conclusion: Respondents in this study are known to have a good picture of physiological and psychological adaptation (adaptive) so that this study can be used in nurses in nursing interventions to further improve patient adaptation to hemodialysis.
\end{abstract}

Keywords: Chronic Renal Failure, Physiological and Psychological Adaptations

\begin{abstract}
Abstrak
Latar Belakang: Penyakit gagal ginjal kronik adalah penyakit yang banyak di derita oleh banyak orang di dunia dari usia muda sampai usia lanjut yang secara signifikan mempengaruhi kemampuan diri dan kualitas hidup karena harus menjalani terapi diantaranya hemodialisis. Untuk meningkatkan kepatuhan maka faktor-faktor penyesuaian diri terhadap terapi hemodialisis perlu di ketahui secara detail. Tujuan: untuk mengetahui gambaran adaptasi fisiologis dan psikologis pada pasien dengan gagal ginjal kronis yang menjalani hemodialisis. Metode: penelitian ini menggunakan metode penelitian deskriptif analitis menggunakan simple random sampling dengan jumlah sampel penelitian 49 pasien yang menjalani hemodialisis. Instrumen penelitian yang di gunakan adalah kuisioner dengan teknik analisis data kuantitatif. Hasil:Responden dalam penelitian ini memiliki adaptasi fisiologis yang baik (adaptive) yaitu 98\% dan juga adaptasi psikologis yang baik yaitu 100\%. Kesimpulan: Responden dalam penelitian ini diketahui memiliki gambaran adaptasi fisiologis dan psikologis yang baik (adaptive) sehingga penelitian ini dapat di gunakan perawat dalam intervensi keperawatan untuk lebih meningkatkan adaptasi pasien dengan hemodialisis.
\end{abstract}

Kata Kunci: Gagal Ginjal Kronis, Adaptasi Fisiologis dan Psikologis. 


\section{PENDAHULUAN}

Gagal ginjal adalah suatu keadaan penurunan fungsi ginjal secara mendadak. Gagal ginjal terjadi ketika ginjal tidak mampu mengangkut sampah metabolik tubuh atau melakukan fungsi regulernya. Suatu bahan yang biasanya di eliminasi di urine menumpuk dalam cairan tubuh akibat gangguan eksresi renal dan menyebabkan gangguan fungsi endokrin dan metabolik, cairan, elektrolit serta asam basa (Harmilah, 2020).

Menurut United States Renal Data System (USRDS) (2018) Proporsi pasien dengan CKD diakui dalam Medicare, jumlah pasien penderita GGK sebelumnya 2,7\% pada tahun 2000 menjadi 13,8\% pada tahun 2016. Prevalensi gagal ginjal kronik (GGK) di Amerika Serikat dengan jumlah penderita meningkat setiap tahunnya. Menurut Alam \& Hadibroto (2007) jumlah penderita gagal ginjal kronik sekitar 80.000 orang, dan tahun 2010 meningkat menjadi 660.000 orang. Menurut data Riskesdas (2018) Prevalensi penyakit ginjal kronis di Indonesia mengalami peningkatan sebesar $0,38 \%$ dari data tahun 2013 dan prevalensi penyakit gagal ginjal di Sulawesi Utara (SULUT) adalah 5\% dari keseluruhan penduduk Indonesia.

Seiring dengan peningkatan jumlah penderita gagal ginjal kronis, maka jumlah pasien yang menjalani dialisis juga meningkat. Yagina (2014) mengemukakan angka kejadian gagal ginjal di dunia secara global lebih dari 500 juta orang dan yang harus menjalani hidup dengan bergantung pada cuci darah (hemodialisis) adalah 1,5 juta orang. Data dari Pernefri (2018) per 31 Desember 2018 pasien GGK yang menjalani dialisis di Indonesia sebanyak 198.275 orang, meningkat dua kali lipat di bandingkan tahun sebelumnya.

Hemodialisis mengakibatkan munculnya beberapa komplikasi yaitu hipotensi dan kram otot, komplikasi tersebut memberikan stressor fisiologis kepada pasien. Selain mendapatkan stressor fisiologis, pasien juga mengalami stressor psikologis. Stressor psikologis diantaranya adalah pembatasan cairan, pembatasan konsumsi makanan, gangguan tidur, ketidakjelasan tentang masa depan, pembatasan aktivitas rekreasi, penurunan kehidupan sosial, pembatasan waktu dan tempat bekerja, serta faktor ekonomi. Pasien akan kehilangan kebebasan karena berbagai aturan dan sangat bergantung kepada tenaga kesehatan, kondisi ini mengakibatkan pasien tidak produktif, pendapatan akan semakin menurun atau bahkan hilang sehingga hal tersebut dapat memengaruhi kualitas hidup. Kelebihan cairan pada pasien HD dapat menimbulkan komplikasi lanjut, seperti hipertensi, aritmia, kardiomiopati, uremic pericarditis, efusi perikardial, gagal jantung, serta edema pulmonal, nyeri pleura, efusi pleura, uremic pleuritis, uremic lung, dan sesak nafas (Prabowo \& Pranata, 2014).

\section{METODE PENELITIAN}

Penelitian ini merupakan penelitian dengan metode deskriptif analitis untuk mendeskripsikan atau memberi gambaran terhadap objek yang diteliti melalui data atau sampel yang telah terkumpul. Penelitian telah di laksanakan di ruangan Hemodialisis salah satu RS Swasta di kota Manado. Jumlah sampel dalam penelitian ini adalah 45 responden yang di ambil dengan teknik simple random sampling.

Instrumen yang di gunakan yaitu kuisioner yang sudah di uji validasi berisi 35 pertanyaan untuk adaptasi fisiologis dan 14 pertanyaan untuk adaptasi psikologis. Dengan perhitungan untuk fungsi fisiologis total skor 70 di katakan adaptif jika skor $>35$ dan maladaptif jika $\leq 35$ dan untuk fungsi fisiologis total skor 28 dikatakan adaptif jika skor $>14$ dan maladaptif jika $\leq 14$.

Penelitian ini menggunakan metode penelitian deskriptif analitis dengan teknik analisis data kuantitatif. Pada saat penelitian, peneliti menerapkan prinsip etika penelitian dan penelitian ini telah mendapat izin dengan nomor surat 053/Komite Etik/SHMN/XI/2020 dan 240/DIR-SHMN/XI/2020. 
Jurnal Keperawatan, Volume 9, No. 2, Agustus 2021, (Hal. 1-6)

\section{HASIL}

Tabel 1. Distribusi Karakteristik Pasien

\begin{tabular}{|c|c|c|c|}
\hline No. & Variabel & $\mathrm{f}$ & $\%$ \\
\hline \multirow[t]{3}{*}{1.} & Jenis Kelamin & & \\
\hline & - Laki-Laki & 25 & $56 \%$ \\
\hline & - Perempuan & 20 & $44 \%$ \\
\hline \multirow[t]{6}{*}{2.} & Usia & & \\
\hline & - 0-14 Tahun & 0 & $0 \%$ \\
\hline & - 15-29 Tahun & 3 & $7 \%$ \\
\hline & - 30-44 Tahun & 6 & $13 \%$ \\
\hline & - 45-64 Tahun & 27 & $60 \%$ \\
\hline & - >65 Tahun & 9 & $20 \%$ \\
\hline \multirow[t]{5}{*}{3.} & Tingkat Pendidikan & & \\
\hline & $-\mathrm{SD}$ & 0 & $0 \%$ \\
\hline & - SMP & 5 & $11 \%$ \\
\hline & - SMA & 19 & $42 \%$ \\
\hline & - Akademi/S1/S2 & 21 & $47 \%$ \\
\hline \multirow[t]{3}{*}{4.} & Pekerjaan & & \\
\hline & - Bekerja & 39 & $87 \%$ \\
\hline & - Tidak Bekerja & 6 & $13 \%$ \\
\hline \multirow[t]{3}{*}{5.} & Lamanya Hemodialisis & & \\
\hline & $-0-12$ bulan & 17 & $38 \%$ \\
\hline & $->1$ tahun & 28 & $62 \%$ \\
\hline \multirow[t]{3}{*}{6.} & Tingkat Adaptasi Fisiologis Pasien & & \\
\hline & - Adaptif & 44 & $98 \%$ \\
\hline & - Maladaptif & 1 & $2 \%$ \\
\hline \multirow[t]{3}{*}{7.} & Tingkat Adaptasi Psikologis Pasien & & \\
\hline & - Adaptif & 45 & $100 \%$ \\
\hline & - Maladaptif & 0 & $0 \%$ \\
\hline
\end{tabular}

Hasil penelitian menunjukkan bahwa pasien gagal ginjal terbanyak adalah laki-laki sebanyak $56 \%$ dan perempuan $44 \%$, presentase usia terbanyak 45-64 tahun sebanyak 60\%, $>65$ tahun 20\%, 30-44 tahun 13\%, dan paling sedikit 15-29 tahun sebanyak 7\% dengan jenjang pendidikan terbanyak adalah jenjang perguruan tinggi yaitu sebanyak $47 \%$. Pasien yang bekerja sebanyak $87 \%$ dan yang tidak bekerja sudah termasuk di dalamnya pensiunan sebanyak 13\%. Pasien terbanyak sudah menjalani dialisis > 1 tahun sebanyak $62 \%$ dan pasien yang di dialisis < tahun sebanyak $38 \%$. Tingkat adaptasi fisiologis pasien mayoritas baik sebanyak $98 \%$ hanya 1 pasien yang maladaptive dan tingkat adaptasi psikologis pasien secara keseluruhan adalah baik.

\section{PEMBAHASAN}

Gambaran Karakteristik Pasien Gagal Ginjal Kronis berdasarkan Tingkat Adaptasi Fisiologis

Hasil penelitian menunjukkan tingkat adaptasi fisiologis mayoritas adalah baik. Kemampuan responden mengontrol regulator dan kognator dalam melakukan aktifitas membuat responden mampu beradaptasi terhadap aktifitas yaitu dengan melakukan aktifitas sesuai dengan kemampuannya. Satu pasien yang maladaptive baru menjalani HD selama 4 
bulan dan mengeluhkan kelemahan fisik, mual, bibir kering dan pembengkakan ekstremitas bawah. Keluhan pasien tersebut menandakan bahwa pasien belum mampu beradapatsi dengan diit pasien HD yaitu rendah cairan, rendah garam dan rendah protein. Pasien yang kakinya bengkak merupakan tanda bahwa pasien mengalami kelebihan cairan. Data pasien ditemukan juga pasien masih bekerja, memiliki tingkat pendidikan yang baik dan sudah di dialisis selama lebih dari 1 tahun.

Tingkat adaptasi pasien yang menjalani hemodialisis sebagai sistem adaptasi dipengaruhi oleh perkembangan individu itu sendiri, dan penggunaan mekanisme koping. Penggunaan mekanisme koping yang maksimal mengembangkan tingkat adaptasi seseorang dan meningkatkan rentang stimulus agar dapat berespon secara positif atau adaptif.

\section{Gambaran Karakteristik Pasien Gagal Ginjal Kronis berdasarkan Tingkat Adaptasi Psikologis}

Hasil penelitian menunjukkan bahwa secara keseluruhan respon penerimaan stress pasien gagal ginjal yang menjalani haemodialisa sebagian besar adalah baik. Hal ini menunjukkan bahwa responden memiliki respon penerimaan stres yang positif karena sudah berada pada tahap penerimaan terhadap penyakit dan terapinya.

Responden $82 \%$ bekerja, sehingga perannya sebagai suami, istri dan pelajar/mahasiswa dapat dilakukan. Penampilan peran merupakan cara individu melakukan peran yang berarti. Peran yang dimaksud mencakup peran sebagai orang tua, pengawas, atau teman dekat. Responden yang adaptif mandiri, aktif dikegiatan keagamaan dan sosial. Responden dapat melakukan peran primer, sekunder dan tertier. Stimulus fokal (faktor-faktor internal dan eksternal yang menyebabkan masalah (penyakit, proses penuaan keseimbangan cairan, stress), stimulus kontekstual (kemampuan dalam perawatan kesehatan, dan gaya hidup; nilai budaya terhadap kesehatan/penyakit) dan stimulus residual (riwayat kesehatan masa lalu dan keluarga; mekanisme koping; pengetahuan terhadap masalah kesehatan) dapat dikendalikan oleh responden dengan mekanisme koping biologis maupun psikologis yang baik, serta respon dari kognator dan regulator yang adaptif, sehingga responden dapat beradaptasi terhadap perannya.

Pasien yang adaptive dengan adaptasi psikologis akan mengalami peningkatan kualitas hidup yang lebih baik. Penyerahan diri kepada Tuhan dan terlebih dukungan dari dalam diri sendiri dan keluarga akan mendorong pasien untuk rajin menjalankan pengobatannya.

\section{SIMPULAN}

Pasien gagal ginjal kronis memiliki gambaran daptasi fisiologis dan psikologis yang baik (adaptive), sehingga penelitian ini dapat di gunakan perawat dalam intervensi keperawatan untuk lebih meningkatkan adaptasi pasien dengan terapi hemodialisis dan perawat dapat meningkatkan kompetensi dalam mengevaluasi pengobatan yang disesuaikan dengan kondisi pasien hemodialisis serta perawat dapat memberikan pendidikan kesehatan dengan berfokus pada pengetahuan, sumber kekuatan internal maupun eksternal yang meningkatkan adaptasi pasien dengan hemodialisis.

\section{DAFTAR PUSTAKA}

Alam, S., \& Hadibroto, I. (2007). Gagal Ginjal. Jakarta: PT Gramedia Pustaka Utama.

Armiyati, Y. (2014). Faktor yang berkorelasi terhadap mekanisme koping pasien CKD yang menjalani hemodialisis di RSUD Kota Semarang.

Bariyyah, N. (2018). Model Adaptasi Pasien Hemodialisis Berbasis Teori 
Modeling Role Modeling di RSUD Provinsi NTB.

Barnett M. (2008). Fluid compliance Among patients having haemodialysis can an educational programmer make a difference?. Journal of advance nursing, Oxford: Feb.61.300.

Brunner \& Suddarth. (2013). Keperawatan Medikal Bedah Brunner dan Suddarth Edisi 12 (Devi Yulianti \& Amelia Kimin, Penerjemah). Jakarta: EGC.

Christensen, P.J. (2016) Proses Keperawatan: Aplikasi Model Konseptual, Edisi 4 (terjemahan yuyun dan yasmin), Jakarta, EGC.

Daugirdas, J., Blake, G., and Ing, T. (2007). Handbook of Dialysis. Lippincott William \& Wilkins.

Dwijayanthi, L. (2012). Ilmu Gizi menjadi sangat mudah. Edisi 2. Jakarta: EGC.

Harmilah, (2020). Asuhan Keperawatan pada Pasien dengan Gangguan Sistem Perkemihan. Yogyakarta: PT Pustaka Baru Press.

Hartono, A. (2004). Terapi Gizi dan Diet Rumah Sakit, Edisi 2. Jakarta: EGC.

Hornblower, S. (2015). Oxford Textbook of Clinical Nephrology. Edited by $\mathrm{N}$.

Turner. Oxford University Press.

Hudson, J. L., Moss-morris, R., Game, D., Carroll, A. And Chilcot, J. (2016) 'Review Article Improving Distress In Dialysis (iDiD): A Tailored CBT Self Management Treatment For Patients undergoing Dialysis', Journal of Renal Care, $\mathrm{XX}(\mathrm{XX})$.

Insani, N., Manggau, M., \& Kasim, H. (2018). Analisis efektivitas terapi pada pasien anemia gagal ginjal hemodialisis di RSUP DR. Wahidin Sudirohusodo Makassar. doi: 10.20956/mff.v22i1.569

Isroin, L. (2016). Manajemen cairan pada pasien hemodialisis untuk meningkatkan kualitas hidup. Umuh Ponorogo Press.

Kardiyudiani., \& Brigita A. (2019). Keperawatan Medikal-Bedah I. Yogyakarta: Pustaka Baru.
Laporan Data United State Renal Data System/URSDS. (2018) Kapita Selekta Kedokteran. Edisi II Jilid 1. Jakarta: Media Aesculapius.

Moore, M. (1997). Buku Pedoman Terapi Diet dan Nutrisi (Liniyanti Oswari \& Melfiawati S, Penerjemah). Jakarta: Hipokrates.

Mosby Year Book, Inc. (1993). Buku Pedoman Terapi Diet dan Nutrisi, Edisi 2 (Liniyanti Oswari, Penerjemah.) Jakarta: Hipokrates. National Kidney Foundation (2017) Chronic Kidney Disease', pp. 13111319. Available at: http://www.nationalkidnecenter.org/ch ronickidneydisease/stages/.

Nursalam, (2006). Asuhan Keperawatan pada Pasien dengan Gangguan Sistem Perkemihan. Jakarta: Salemba Medika.

Nurchayati. (2010). Analisis Faktor-faktor yang berhubungan dengan kualitas hidup pasien penyakit ginjal kronik yang menjalani hemodialisis di RS Islam Fatimah Cilacap dan Rumah Sakit Umum Daerah Banyumas.

Onofrio, G.D., Simeoni, M., \& Rizza, P. (2016) 'Quality of life, clinical outcome, personality and coping in chronic hemodialysis patients', Renal Failure. Informa Healthcare USA, Inc.

Pebriantari, G., \& Iga, D. (2017). Hubungan komplikasi intra hemodialisis dengan kualitas hidup pada pasien Chronic Kidney Disease $(C K D)$ Stage $V$ yang menjalani hemodialisis di ruangan hemodialisa BRSU Tabanan.

Perhimpunan Nefrologi Indonesia. (2018). Available at https://www.google.com/search?q pernefri+2018\&rlz=1C1RLNS_en D783ID783\&oq=pernefri $+2018 \&$ qs $=$ chrome...69i57j0i22i3012.2792 $0 \mathrm{j} 7 \&$ sourceid $=$ chrome $\& \mathrm{ie}=\mathrm{UTF}-8$

Prabowo, E., \& Pranata, E. (2014). Asuhan Keperawatan Sistem Perkemihan 
(Edisi 1). Yogyakarta: Nuha Medika.

Price, S., \& Wilson L. M. (2013).

Patofisiologi dan konsep klinis Proses penyakit.Edisi 6. Jakarta: Penerbit Buku Kedokteran, EGC.

Riskesdas. (2018). Sampel RUTA Riskesdas available at https://www.google.com/search?q

RISKESDAS+2018\&rlz=1C1RLS_en ID783ID783\&oq=riskes\&aq=chrome. 0.69i59j69i57j0j0i433j01.1358j0j7\&so urceid $=$ chrome $\& i e=$ TF- 8 .

Setiadi, (2013). Konsep dan Praktek Penulisan Riset Keperawatan Edisi 2. Yogyakarta: Graha Ilmu

Setiawan, A. (2018). Hubungan Dukungan Keluarga dengan Keberhasilan Adaptasi pada Pasien DM yang Mengalami Gangren di RSUD Kota Madiun. PRO Keperawatan STIKES Bhakti Husada Madiun.

Smeltzer, S. (2010). Keperawatan Medikal-Bedah Brunner \& Suddarth. Edisi 12 (Devi Yulianto \& Amelia Kimin, Penerjemah) Jakarta: EGC.

Sukmawati., \& Rosita Y. (2008). Hubungan antar konsep diri dengan kecenderungan depresi ada remaja. Jurnal \& Psikohumanika. Volume 1.

Sumigar, G., Rompas, S., \& Pondaag, L. (2015). Hubungan dukungan keluarga dengan kepatuhan diet pada pasien gagal ginjal kronik di Irina C2 dan C4 RSUP. Prof. Dr. R. D. Kandou Manado.Volume 1.

Suwitra, K.(2009). Penyakit Ginjal Kronik Edisi 3. (Sudoyo AW, Setiyohadi B, Alwi I, et al., Penerjemah). Jakarta: Interna Publishing.

The ESRD Incidence Study Group: Geographic, ethnic, age related and temporal variation in the incidence of endstage renal disease in Europe, Canada and the Asia-Pacific region, 1998 2002. Nephrol Dia Transplant April 4, 2006.

Urquhart-secord, R., Craig, J.C., \& Hemmelgarn, B., (2016) 'Patient and Caregiver Priorities for Outcomes in Hemodialysis: An International
Nominal Group Technique Study', American Journal of Kidney Diseases. Elsevier Inc. Vic \& Karabacak. (2016). Role Of Laboratory In The Era Of Personalized Medicine. Konsensus Acute Dyalisis Quality Initiative, Venesia, Italia.

Wan, Y.F., Chen, J.Y., \& Choi, P.H. (2015) Patterns of Health-related Quality of Life and Associated Factors in Chinese Patients undergoing Haemodialysis', Health and Quality of Life Outcomes. Health and Quality of Life Outcomes.

Yagina. (2014). Buku Ajar Keperawatan Medikal-Bedah. Jakarta: Yayasan Ginjal Diatrash Indonesia (YAGINA).

Yilmaz, S., Yildirim,Y., \& Yilmaz, Z. (2016) 'Pulmonary Function in Patients with End-Stage Renal Disease: Effects of Hemodialysis and Fluid Overload', Med Sci Monit. 